\title{
IRRIGATION AND NITROGEN MANAGEMENT PRACTICES AFFECT GRAIN YIELD AND 2-ACETYL-1-PYRROLINE CONTENT IN AROMATIC RICE
}

\author{
REN, Y. ${ }^{1,2 \dagger}-$ ASHRAF, U. ${ }^{1,2 \dagger}-$ HE, L. X. ${ }^{1,2 \dagger}-$ MO, Z. W. ${ }^{1,2}-$ WANG, F. ${ }^{1,2}-$ WAN, X. C. ${ }^{1,2}-$ \\ KONG, H. ${ }^{1,2}-$ RAN, X. L. ${ }^{1,2}-$ TANG, X. R. ${ }^{1,2^{*}}$ \\ ${ }^{I}$ Department of Crop Science and Technology, College of Agriculture, South China Agricultural \\ University, Guangzhou, Guangdong 510642, China \\ ${ }^{2}$ Scientific Observing and Experimental Station of Crop Cultivation in South China, Ministry of \\ Agriculture of the P. R. China, Guangzhou, Guangdong 510642, China \\ ${ }^{\dagger}$ These authors have contributed equally to this work. \\ *Corresponding author \\ e-mail: tangxr@scau.edu.cn; phone/fax:+20-8528-0204-618 \\ (Received 28 ${ }^{\text {th }}$ May 2017; accepted $2^{\text {nd }}$ Aug 2017)
}

\begin{abstract}
Aromatic rice has a high market value due to its special fragrance and the most important compound in the grains of aromatic rice is 2-acetyl-1-pyrroline (2-AP). In an effort to improve the 2-AP content and the yield of aromatic rice, two known rice cultivars, Yungao and Yundi, were cultivated across two seasons, and two irrigation and nitrogen management practices were investigated. The results showed that the treatment management practice (TNW) treatment improved panicle number per hill, seed setting rate, and 1000 grain weight and grain yield for both cultivars in early and late season. Significant improvement in grain yield was only observed in Yundi in both seasons. Moreover, the 2-AP content in grains was increased for both cultivars in both seasons during grain filling period. Significant increase in 2-AP in grains was observed for Yungao at maturity in both seasons, at $7 \mathrm{~d}$ AH in early season and at $14 \mathrm{~d}$ $\mathrm{AH}$ in late season whilst for Yundi at $7 \mathrm{~d}$ AH, $14 \mathrm{~d}$ AH and $21 \mathrm{~d}$ AH in early season, and at $14 \mathrm{~d}$ AH in late season. Furthermore, 2-AP content in leaves and grains was decrease during grain filling period while proline content in grains was enhanced during grain filling period. Significant relationships were also observed between 2-AP and proline contents in the leaves/grains of both rice cultivars.
\end{abstract}

Keywords: aromatic rice; 2-acetyl-1-pyrroline; proline; nitrogen; irrigation

\section{Introduction}

Rice is one of the most important cereal crops and feeds billions of people around the world. Aromatic rice, such as Basmati and Jasmine, has a characteristic fragrance and good grain quality (Ashraf et al., 2017; Ashraf and Tang, 2017). The aromatic rice grains valued at a higher market price than non-aromatic rice varieties (Zhang et al., 2008). Since the 1980s, numerous studies have investigated hundreds of fragrant compounds in scented rice grains and identified the 2-acetyl-1-pyrroline (2-AP) as the key fragrant 
compound of aromatic rice (Yajima et al., 1979; Buttery et al., 1982; Widjaja et al., 1996; Champagne, 2008).

The 2-AP accumulation in aromatic rice is affected by many environmental factors during aromatic rice growth. For example, high night temperature reduced grain quality remarkably (Mohammed and Tarpley, 2010; Nagarajan et al., 2010). During grain filling period, shading treatments significantly improved the 2-AP content and $\gamma$-aminobutyric acid (GABA) content in aromatic rice grains (Mo et al., 2015). With salt stress treatment, the popular aromatic rice (Khao Dawk Mali 105) cells accumulated $\mathrm{Na}^{+}$and proline (Summart et al., 2010) whilst the reduction of fragrant rice yield was related to the fragrance in rice (Fitzgerald et al., 2010). Moreover, some studies reported that salt stress can increase 2-AP content in grains (Gay et al., 2010; Poonlaphdecha et al., 2012). Some minor elements were also found to be associated with 2-AP accumulation in aromatic rice (Lei et al., 2017). Manganese (Mn) application had a positive effect on rice yield, quality and 2-AP content ( $\mathrm{Li}$ et al. 2016). 2-AP content and proline dehydrogenase (ProDH) activity were increased by moderate concentration of zinc ( $\mathrm{Zn}$ ) and lanthanum (La) treatment (Mo et al., 2016). Furthermore, silicon fertilization also modulates 2-acetyl-1-pyrroline content $\mathrm{n}$ fragrant rice (Mo et al., 2017).

Many previous studies have reported that nitrogen and water as important aspects for aromatic rice growth and development. The nitrogen utilization efficiency is associated to the rice genotypes and locations (Djaman et al., 2016). Sikdar et al. (2008) found that N level at $80 \mathrm{~kg} / \mathrm{hm}^{2}$ improved grain quality and soil fertility. However, high nitrogen can lead to lodging in rice (Mahajan et al., 2010). In Asia, rice production is limited due to water shortage (Arora et al., 2006), thus, irrigation patterns directly influence rice production. Alternating wetitnng and drying could regulate rice yield (Zhang et al., 2012), whilst moderate irrigation control can also have a positive impact on 2-AP content and grain yield of aromatic rice (Yoshihashi et al., 2002; Tian et al., 2014). Hakoomat et al. (2014) found the $\mathrm{N}$ and $\mathrm{Zn}$ interactions had the most significant improvement on yield and yield related traits when the $\mathrm{N}$ level was $12 \mathrm{~kg} / \mathrm{hm}^{2}$ and $\mathrm{Zn}$ level was $14 \mathrm{~kg} / \mathrm{hm}^{2}$. Moreover, moderate irrigation at tillering, booting, and grain filling stage could increase the 2-AP content in grains (Tian et al., 2010; Wang et al., 2013a, b). Yang et al. (2012) reported high aroma content in grains was associated to high total nitrogen in soil. Zhong and Tang (2014) found that 2-AP content in grains was increased with increasing nitrogen application. Li et al. (2014) found the 2-AP content in brown rice was highest when the $\mathrm{N}$ supply was $60 \mathrm{~kg} / \mathrm{hm}^{2}$ and the irrigation potential was $-20 \mathrm{kPa}$ at tillering stage.

In our previous studies, we have investigated the interaction effect of water and nitrogen at tillering stage ( $\mathrm{Li}$ et al., 2014), booting stage and grain filling stage on grain yield and 2-AP accumulation in grains (data unpublished), then, we selected the best water and nitrogen treatment of the three stages and combined the treatments together for investigating the additive effect of the nitrogen and water management treatment on aromatic rice yield and 2-AP accumulation. In this study, we aimed to identify the affects of the combinations of water and nitrogen applications implemented at tillering stage, booting stage, and grain filling stage on 2-AP accumulation and grain yield. 


\section{Materials and Methods}

\section{Plant materials and growing condition}

Two popular aromatic rice cultivars, Yungao and Yundi, having 115 -120 days of growth period were planted in early season and late season in 2015 at the College of Agriculture, South China Agricultural University, Guangzhou, China (23⒉ ${ }^{\prime}$ N, $113^{\circ} 30^{\prime}$ $\mathrm{E}$ and $11 \mathrm{~m}$ above the sea level. The experimental site has a subtropical-monsoon type climate with mean annual air temperatures of $22.4{ }^{\circ} \mathrm{C}$ and mean annual precipitation of $2638.3 \mathrm{~mm}$ (Fig. 1). The seeds were soaked in water for $24 \mathrm{~h}$, germinated in manual climatic box for the next 24h, and raised at the Research Farm of the College Agriculture. 30-day-old seedlings were transplanted to the field at the recommended planting distance $(30 \mathrm{~cm} \times 12 \mathrm{~cm})$. The experimetal soil was sandy loam with of $25.65 \%$ organic matter content, $1.362 \%$ total $\mathrm{N}, 0.958 \%$ total $\mathrm{P}$, and $17.520 \%$ total $\mathrm{K}$.

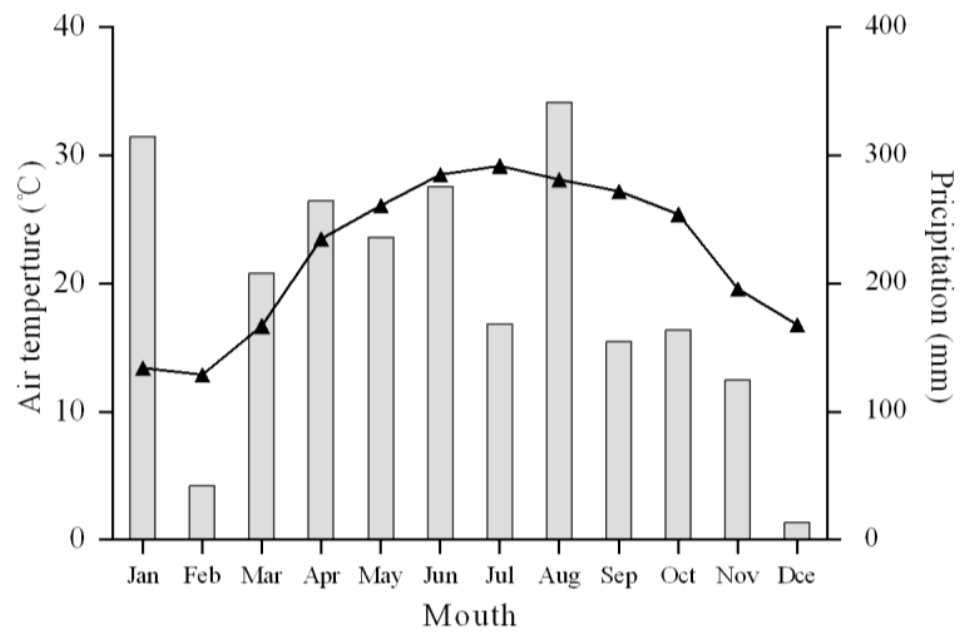

Figure 1. Mean monthly temperature and precipitation in 2016 of the experimental site

\section{Treatments and plant sampling}

The experiment was conducted in early season and repeated in late season. Experimental treatments are as follows: (i) The conventional management practice (CK) involves applying nitrogen $\left(30 \mathrm{~kg} / \mathrm{hm}^{2}\right)$ at tillering stage, booting stage, and grain filling stage; the water flow at these three stages was $0 \mathrm{kPa}$ in both early and late season rice. (ii) The treatment management practice involved applying nitrogen $\left(60 \mathrm{~kg} / \mathrm{hm}^{2}\right)$ at tillering stage with heavy drought conditions (water potential of - $(25 \pm 5) \mathrm{kPa}$ ), applying 60 $\mathrm{kg} / \mathrm{hm}^{2}$ nitrogen at the booting stage with feebly arid conditions (water potential of $(15 \pm 5) \mathrm{kPa})$, and applying no nitrogen at the grain filling stage with shallow-watered irrigation (water flow of $0 \mathrm{kPa})(\mathrm{TNW}) . \mathrm{P}_{2} \mathrm{O}_{5}\left(90 \mathrm{~kg} / \mathrm{hm}^{2}\right), \mathrm{K}_{2} \mathrm{O}\left(195 \mathrm{~kg} / \mathrm{hm}^{2}\right)$ were applied as basic fertilizer. The fresh leaves and grains were sampled from the rice at the end of tillering stage; after 7, 14, and 21 d heading stage; and at maturity. Samples were immediately stored at $-20^{\circ} \mathrm{C}$ for 2 -AP analysis. 


\section{Yield and yield related traits}

At maturity, the grains were harvested from one unit sampling area $\left(8.1 \mathrm{~m}^{2}\right)$ in each plot and threshed by machine. The harvested grains were sundried, and the dry weight was used to estimate the grain yield. Thirty hills of rice plants from different locations in each plot were sampled for calculating the average effective panicles number per hill. Then, three hills representative plants were taken for determination of the yield related traits.

\section{Proline estimation}

The proline content in leaves and grains were measured according to the method established by Bates et al. (1973). Leaves or grains in which the weight was almost $0.3 \mathrm{~g}$, were homogenized in a $4 \mathrm{ml}$ solution of $3 \%$ sulfosalicylic acid and cooled after bringing to a boil for $10 \mathrm{~min}$. Samples were filtered and $2 \mathrm{ml}$ of the filtrate was mixed with $3 \mathrm{~mL}$ ninhydrin reagent $(2.5 \mathrm{~g}$ ninhydrin in $60 \mathrm{~mL}$ glacial acetic acid and $40 \mathrm{~mL} 6 \mathrm{M}$ phosphoric acid) and $2 \mathrm{~mL}$ glacial acetic acid. For the extraction of proline, the mixture was boiled for $30 \mathrm{~min}$ and $4 \mathrm{~mL}$ toluene was added to the cooled liquid. The extract was centrifuged at 4000rpm for $5 \mathrm{~min}$, and proline absorbance was detected at $520 \mathrm{~nm}$. The proline concentration, expressed as $\mu \mathrm{g} \cdot \mathrm{g}^{-1}$, was assayed by using standard curve to calibrate.

\section{2-AP estimation}

The 2-AP content was estimated using the method described by Huang et al. (2012), Prior to analysis, leaves were cut into sections and grains were ground by mortar and pestle. Approximately $5 \mathrm{~g}$ leaves or $10 \mathrm{~g}$ grains were mixed homogeneously with $150 \mathrm{~mL}$ purified water into a $500 \mathrm{~mL}$ round-bottom flask attached to a continuous steam distillation extraction head. The mixture was boiled at $150^{\circ} \mathrm{C}$ in an oil pot. A $30 \mathrm{~mL}$ aliquot of dichloromethane was used as the extraction solvent and was added to a $500 \mathrm{~mL}$ round-bottom flask attached the other head of the continuous steam distillation apparatus, and this flask was boiled in a water pot at $53^{\circ} \mathrm{C}$. The continuous steam distillation extraction was linked with a cold water circulation machine in order to keep temperature at $10^{\circ} \mathrm{C}$. After approximately $35 \mathrm{~min}$, the extraction was complete. Anhydrous sodium sulfite was added to the extract to absorb the water. The dried extract was filtered by organic needle filter and analyzed for 2-AP content by GCMS-QP 2010 Plus. High purity helium gas was used as the carrier gas at flow rate of $2 \mathrm{~mL} / \mathrm{min}$. The temperature gradient of the GC oven was as follows: $40^{\circ} \mathrm{C}(1 \mathrm{~min})$, increased at $2^{\circ} \mathrm{C} \cdot \mathrm{min}^{-1}$ to $65^{\circ} \mathrm{C}$ and held at $65^{\circ} \mathrm{C}$ for $1 \mathrm{~min}$, and then increased to $220^{\circ} \mathrm{C}$ at $10^{\circ} \mathrm{C} \cdot \mathrm{min}^{-1}$, and held at $220^{\circ} \mathrm{C}$ for $10 \mathrm{~min}$. The retention time of 2-AP was confirmed at $7.5 \mathrm{~min}$. Each sample had three replicates, and 2-AP was expressed as $\mu \mathrm{g} \cdot \mathrm{kg}^{-1}$. 


\section{Treatment design and statistical analysis}

This study was arranged as a randomized complete block design (RCBD) with three replicates $(n=3)$. Data were analyzed by SPSS 16.0 software (SPSS Inc., Chicago, USA), and the probability level was set at $5 \%(\mathrm{P}<0.05)$.

\section{Results}

\section{Grain yield and yield related traits}

As shown in Table 1, the panicle number per hill, seed-setting rate, and 1000-grain weight and yield were higher in TNW treatment than in CK for Yungao and Yundi in both seasons. The seed setting rate was significantly improved by $11.75 \%$ in TNW treatment for Yundi in late season. The grain yield was dramatically increased by $12.13 \%$ and $21.00 \%$ for Yundi in early and late season, respectively. CK treatment had higher grain number per panicle than TNW treatment in Yungao and Yundi in both seasons.

Table 1. Effects of irrigation and nitrogen management practices on yield and yield related traits in aromatic rice

\begin{tabular}{|c|c|c|c|c|c|c|c|}
\hline Season & Cultivar & Treatment & $\begin{array}{l}\text { Panicle } \\
\text { number per } \\
\text { hill }\end{array}$ & $\begin{array}{c}\text { Grains number } \\
\text { per panicle }\end{array}$ & $\begin{array}{c}\text { Seed-setting } \\
\text { rate }(\%)\end{array}$ & $\begin{array}{r}\text { 1000-grain } \\
\text { weight } \\
(\mathrm{g})\end{array}$ & $\begin{array}{r}\text { Yield } \\
\left(\mathrm{t} \mathrm{hm}^{-2}\right)\end{array}$ \\
\hline \multirow{4}{*}{$\begin{array}{l}\text { Early } \\
\text { season }\end{array}$} & Yungao & CK & $14.03 \pm 0.62 \mathrm{a}$ & $82.52 \pm 2.07 \mathrm{a}$ & $87.24 \pm 0.81 \mathrm{a}$ & $25.13 \pm 0.08 \mathrm{a}$ & $5.16 \pm 0.45 a$ \\
\hline & & TNW & $15.48 \pm 0.71 \mathrm{a}$ & $74.92 \pm 1.50 \mathrm{a}$ & $88.58 \pm 2.37 \mathrm{a}$ & $26.20 \pm 0.51 \mathrm{a}$ & $5.74 \pm 0.38 \mathrm{a}$ \\
\hline & Yundi & CK & $13.05 \pm 0.48 \mathrm{a}$ & $108.80 \pm 8.96 \mathrm{a}$ & $88.60 \pm 1.70 \mathrm{a}$ & $24.68 \pm 0.12 \mathrm{a}$ & $5.36 \pm 0.20 \mathrm{~b}$ \\
\hline & & TNW & $13.30 \pm 0.55 \mathrm{a}$ & $93.68 \pm 4.00 \mathrm{a}$ & $90.25 \pm 0.96 \mathrm{a}$ & $24.85 \pm 0.30 \mathrm{a}$ & $6.01 \pm 0.07 \mathrm{a}$ \\
\hline \multirow{4}{*}{$\begin{array}{l}\text { Late } \\
\text { season }\end{array}$} & Yungao & CK & $12.76 \pm 0.49 \mathrm{a}$ & $111.00 \pm 5.41 \mathrm{a}$ & $81.98 \pm 4.72 \mathrm{a}$ & $25.88 \pm 0.22 \mathrm{a}$ & $4.59 \pm 0.27 \mathrm{a}$ \\
\hline & & TNW & $13.00 \pm 0.57 \mathrm{a}$ & $108.49 \pm 4.12 \mathrm{a}$ & $86.10 \pm 0.78 \mathrm{a}$ & $26.50 \pm 0.44 \mathrm{a}$ & $4.73 \pm 0.14 \mathrm{a}$ \\
\hline & Yundi & CK & $12.69 \pm 0.47 \mathrm{a}$ & $114.82 \pm 3.40 \mathrm{a}$ & $79.97 \pm 2.33 b$ & $24.03 \pm 0.13 \mathrm{a}$ & $4.81 \pm 0.08 \mathrm{~b}$ \\
\hline & & TNW & $12.77 \pm 0.47 \mathrm{a}$ & $109.65 \pm 10.79 \mathrm{a}$ & $89.37 \pm 2.34 \mathrm{a}$ & $24.60 \pm 0.44 \mathrm{a}$ & $5.82 \pm 0.07 \mathrm{a}$ \\
\hline
\end{tabular}

Means in the same column followed by different lower case letters for the same variety differ significantly at $\mathrm{P}<0.05$ by T-test. CK (control); TNW $\left(60 \mathrm{~kg} / \mathrm{hm}^{2}\right.$ nitrogen and water potential of $-(25 \pm 5) \mathrm{kPa}$ ) were applied at the tilling stage, $60 \mathrm{~kg} / \mathrm{hm}^{2}$ nitrogen and water potential of $-(15 \pm 5) \mathrm{kPa}$ were applied at the booting stage, no nitrogen and water flow of $0 \mathrm{kPa}$ were applied at the grain filling stage)

\section{2-AP content in grains}

We observed higher 2-AP content in grains in TNW treatment than $\mathrm{CK}$ for both cultivars at all the sampling stages in the early and late season. For Yungao, the 2-AP content in grains were significantly increased by $61.88 \%$ and $31.10 \%$ at $7 \mathrm{~d} \mathrm{AH}$ and maturity in early season, respectively; significant increase in 2-AP content in grains by 
$79.02 \%$ and $13.88 \%$ were observed at $14 \mathrm{~d} \mathrm{AH}$ and maturity in late season, respectively. For Yundi, the 2-AP content in grains in TNW treatment were remarkably higher than CK at $7 \mathrm{~d} \mathrm{AH}, 14 \mathrm{~d} \mathrm{AH}$ and $21 \mathrm{~d} \mathrm{AH}$ in early season; significant improved in 2-AP content in grains by $12.07 \%$ was found at $14 \mathrm{~d} \mathrm{AH}$ in late season.

Table 2. Effects of irrigation and nitrogen management practices on 2-AP content of grains at different stages $\left(\mu \mathrm{g} \cdot \mathrm{kg}^{-1}\right)$

\begin{tabular}{ccccccc}
\hline Season & Cultivar & Treatment & $7 \mathrm{~d} \mathrm{AH}$ & $14 \mathrm{~d} \mathrm{AH}$ & $21 \mathrm{~d}$ AH & Maturity \\
\hline Early & Yungao & CK & $102.01 \pm 0.46 \mathrm{~b}$ & $115.56 \pm 5.75 \mathrm{a}$ & $145.84 \pm 8.09 \mathrm{a}$ & $387.30 \pm 24.94 \mathrm{~b}$ \\
season & & TNW & $165.13 \pm 6.80 \mathrm{a}$ & $129.26 \pm 5.21 \mathrm{a}$ & $146.11 \pm 3.41 \mathrm{a}$ & $507.76 \pm 27.14 \mathrm{a}$ \\
& Yundi & CK & $119.68 \pm 2.35 \mathrm{~b}$ & $67.55 \pm 1.01 \mathrm{~b}$ & $94.46 \pm 5.75 \mathrm{~b}$ & $104.42 \pm 11.50 \mathrm{a}$ \\
& & TNW & $176.14 \pm 1.82 \mathrm{a}$ & $124.14 \pm 3.96 \mathrm{a}$ & $119.07 \pm 2.21 \mathrm{a}$ & $120.91 \pm 2.88 \mathrm{a}$ \\
\hline \multirow{2}{*}{ Late } & Yungao & CK & $139.24 \pm 0.22 \mathrm{a}$ & $126.77 \pm 1.12 \mathrm{~b}$ & $140.77 \pm 3.17 \mathrm{a}$ & $255.99 \pm 3.01 \mathrm{~b}$ \\
season & & TNW & $140.65 \pm 1.22 \mathrm{a}$ & $226.94 \pm 5.48 \mathrm{a}$ & $146.54 \pm 0.07 \mathrm{a}$ & $291.51 \pm 8.48 \mathrm{a}$ \\
& Yundi & CK & $146.43 \pm 0.85 \mathrm{a}$ & $233.22 \pm 4.00 \mathrm{~b}$ & $164.51 \pm 7.47 \mathrm{a}$ & $327.59 \pm 1.44 \mathrm{a}$ \\
& & TNW & $164.93 \pm 5.17 \mathrm{a}$ & $261.36 \pm 5.93 \mathrm{a}$ & $176.73 \pm 6.73 \mathrm{a}$ & $336.91 \pm 3.11 \mathrm{a}$ \\
\hline
\end{tabular}

Means in the same column followed by different lower case letters for the same variety differ significantly at $\mathrm{P}<0.05$ by T-test. AH=after heading; CK (control); TNW (60 $\mathrm{kg} / \mathrm{hm}^{2}$ nitrogen and water potential of - $\left.(25 \pm 5) \mathrm{kPa}\right)$ were applied at the tilling stage, 60 $\mathrm{kg} / \mathrm{hm}^{2}$ nitrogen and water potential of $-(15 \pm 5) \mathrm{kPa}$ were applied at the booting stage, no nitrogen and water flow of $0 \mathrm{kPa}$ were applied at the grain filling stage)

\section{2-AP content in leaves}

Table 3 shows that TNW treatment decrease 2-AP content in leaves at all the sampling stages. In early season, 2-AP content in leaves were significantly decreased except for $21 \mathrm{~d}$ $\mathrm{AH}$ and $14 \mathrm{~d}$ AH for Yungao and Yundi, respectively. The 2-AP content in leaves in TNW treatment decreased for both rice cultivars at $14 \mathrm{~d} \mathrm{AH}$, and for Yungao at the maturity.

Table 3. Effects of irrigation and nitrogen management practices on 2-AP content of leaves at different stages $\left(\mu \mathrm{g} \cdot \mathrm{kg}^{-1}\right)$

\begin{tabular}{ccccccc}
\hline Season & Cultivar & Treatment & $7 \mathrm{~d}$ AH & $14 \mathrm{dAH}$ & $21 \mathrm{~d}$ AH & Maturity \\
\hline Early & Yungao & $\mathrm{CK}$ & $401.96 \pm 4.12 \mathrm{a}$ & $245.84 \pm 16.62 \mathrm{a}$ & $109.84 \pm 2.61 \mathrm{a}$ & $418.81 \pm 7.14 \mathrm{a}$ \\
season & & TNW & $342.24 \pm 11.31 \mathrm{~b}$ & $121.43 \pm 4.21 \mathrm{~b}$ & $109.51 \pm 0.16 \mathrm{a}$ & $284.18 \pm 0.58 \mathrm{~b}$ \\
& Yundi & $\mathrm{CK}$ & $356.64 \pm 6.33 \mathrm{a}$ & $212.29 \pm 7.24 \mathrm{a}$ & $221.28 \pm 6.60 \mathrm{a}$ & $217.18 \pm 5.18 \mathrm{a}$ \\
& & TNW & $112.16 \pm 6.57 \mathrm{~b}$ & $211.61 \pm 3.73 \mathrm{a}$ & $117.84 \pm 6.60 \mathrm{~b}$ & $112.13 \pm 3.30 \mathrm{~b}$ \\
\hline \multirow{2}{*}{ Late } & Yungao & CK & $347.59 \pm 5.19 \mathrm{a}$ & $200.41 \pm 6.73 \mathrm{a}$ & $238.54 \pm 4.61 \mathrm{a}$ & $238.57 \pm 10.19 \mathrm{a}$ \\
season & & TNW & $239.16 \pm 11.31 \mathrm{~b}$ & $190.39 \pm 2.90 \mathrm{a}$ & $217.04 \pm 6.33 \mathrm{a}$ & $199.82 \pm 2.70 \mathrm{~b}$ \\
& Yundi & CK & $343.59 \pm 2.56 \mathrm{a}$ & $170.41 \pm 4.97 \mathrm{a}$ & $209.46 \pm 12.09 \mathrm{a}$ & $198.72 \pm 15.5 \mathrm{a}$ \\
& & TNW & $283.23 \pm 11.49 \mathrm{~b}$ & $167.32 \pm 5.78 \mathrm{a}$ & $199.58 \pm 0.85 \mathrm{a}$ & $197.52 \pm 5.77 \mathrm{a}$ \\
\hline
\end{tabular}


Means in the same column followed by different lower case letters for the same variety differ significantly at $\mathrm{P}<0.05$ by T-test. AH=after heading; $\mathrm{CK}$ (control); TNW (60 $\mathrm{kg} / \mathrm{hm}^{2}$ nitrogen and water potential of $\left.-(25 \pm 5) \mathrm{kPa}\right)$ were applied at the tilling stage, 60 $\mathrm{kg} / \mathrm{hm}^{2}$ nitrogen and water potential of $-(15 \pm 5) \mathrm{kPa}$ were applied at the booting stage, no nitrogen and water flow of $0 \mathrm{kPa}$ were applied at the grain filling stage)

\section{Proline content in grains}

The proline content in grains increased at all the sampling stages during grain filling in the early and late season. For Yungao, the proline content significantly enhanced at $21 \mathrm{~d}$ $\mathrm{AH}$ and maturity in early season and remarkably increased at $7 \mathrm{~d} \mathrm{AH}, 14 \mathrm{~d} \mathrm{AH}$ and $21 \mathrm{~d}$ $\mathrm{AH}$ in the late season. For Yundi, TNW treatment significantly increased proline content in grains at $7 \mathrm{~d}$ AH in early season, significantly improved proline content in grains at $7 \mathrm{~d}$ $\mathrm{AH}$ and $14 \mathrm{~d} \mathrm{AH}$ in late season was observed (Table 4).

Table 4. Effects of irrigation and nitrogen management practices on proline content on grains at different stages $(\mu g \cdot g-1)$

\begin{tabular}{ccccccc}
\hline Season & Cultivar & Treatment & $7 \mathrm{~d} \mathrm{AH}$ & $14 \mathrm{~d} \mathrm{AH}$ & $21 \mathrm{~d}$ AH & Maturity \\
\hline Early & Yungao & CK & $41.17 \pm 3.72 \mathrm{a}$ & $46.82 \pm 2.44 \mathrm{a}$ & $28.11 \pm 0.17 \mathrm{~b}$ & $25.31 \pm 0.04 \mathrm{~b}$ \\
season & & TNW & $48.89 \pm 0.39 \mathrm{a}$ & $47.45 \pm 3.13 \mathrm{a}$ & $36.77 \pm 0.27 \mathrm{a}$ & $26.53 \pm 0.05 \mathrm{a}$ \\
& Yundi & CK & $20.60 \pm 0.46 \mathrm{~b}$ & $14.69 \pm 0.98 \mathrm{a}$ & $22.58 \pm 0.07 \mathrm{a}$ & $22.52 \pm 0.03 \mathrm{a}$ \\
& & TNW & $45.66 \pm 1.73 \mathrm{a}$ & $20.91 \pm 4.30 \mathrm{a}$ & $22.71 \pm 1.21 \mathrm{a}$ & $23.64 \pm 0.77 \mathrm{a}$ \\
\hline \multirow{2}{*}{ Late } & Yungao & CK & $43.23 \pm 1.80 \mathrm{~b}$ & $61.02 \pm 3.10 \mathrm{~b}$ & $43.84 \pm 0.85 \mathrm{~b}$ & $7.36 \pm 0.80 \mathrm{a}$ \\
season & & TNW & $52.97 \pm 1.97 \mathrm{a}$ & $79.79 \pm 1.53 \mathrm{a}$ & $60.42 \pm 1.37 \mathrm{a}$ & $9.50 \pm 0.79 \mathrm{a}$ \\
& Yundi & CK & $44.70 \pm 6.39 \mathrm{~b}$ & $42.22 \pm 3.03 \mathrm{~b}$ & $30.41 \pm 4.00 \mathrm{a}$ & $5.26 \pm 1.56 \mathrm{a}$ \\
& & TNW & $48.84 \pm 2.57 \mathrm{a}$ & $56.09 \pm 2.30 \mathrm{a}$ & $35.51 \pm 0.98 \mathrm{a}$ & $8.13 \pm 1.76 \mathrm{a}$ \\
\hline
\end{tabular}

Means in the same column followed by different lower case letters for the same variety differ significantly at $\mathrm{P}<0.05$ by T-test. $\mathrm{AH}=$ after heading; $\mathrm{CK}$ (control); TNW (60 $\mathrm{kg} / \mathrm{hm}^{2}$ nitrogen and water potential of - $\left.(25 \pm 5) \mathrm{kPa}\right)$ were applied at the tilling stage, 60 $\mathrm{kg} / \mathrm{hm}^{2}$ nitrogen and water potential of $-(15 \pm 5) \mathrm{kPa}$ were applied at the booting stage, no nitrogen and water flow of $0 \mathrm{kPa}$ were applied at the grain filling stage).

\section{Proline content in leaves}

We observed a decrease in proline content in leaves at all the sampling stages in the early and late season. For Yungao, significant decreased in proline in leaves was found at the $7 \mathrm{~d} \mathrm{AH}$ and maturity in the early season; a significant decrease in proline in leaves was detected at $7 \mathrm{~d} \mathrm{AH}, 14 \mathrm{~d} \mathrm{AH}$ and $21 \mathrm{~d} \mathrm{AH}$ in late season. For Yundi, TNW treatment showed significantly lower in proline content in leaves than $\mathrm{CK}$ at $7 \mathrm{~d} \mathrm{AH}, 21 \mathrm{~d} \mathrm{AH}$ and Maturity in early season, and at $7 \mathrm{~d} \mathrm{AH}$ and $14 \mathrm{~d} \mathrm{AH}$ in late season (Table 5). 
Ren et al.: Effects of irrigation and nitrogen management practices on 2-acetyl-1-pyrroline content and grain yield formation in aromatic rice

$-1454-$

Table 5. Effects of irrigation and nitrogen management practices on proline content in leaves at different stages $\left(\mu \mathrm{g} \cdot \mathrm{g}^{-1}\right)$

\begin{tabular}{ccccccc}
\hline Season & Cultivar & Treatment & $7 \mathrm{~d} \mathrm{AH}$ & $14 \mathrm{~d} \mathrm{AH}$ & $21 \mathrm{~d}$ AH & Maturity \\
\hline Early & Yungao & CK & $99.37 \pm 4.04 \mathrm{a}$ & $52.14 \pm 3.59 \mathrm{a}$ & $15.31 \pm 1.32 \mathrm{a}$ & $22.08 \pm 0.82 \mathrm{a}$ \\
season & & TNW & $86.78 \pm 0.40 \mathrm{~b}$ & $45.99 \pm 2.77 \mathrm{a}$ & $14.33 \pm 0.09 \mathrm{a}$ & $17.62 \pm 0.81 \mathrm{~b}$ \\
& Yundi & CK & $94.55 \pm 1.00 \mathrm{a}$ & $67.94 \pm 0.32 \mathrm{a}$ & $20.72 \pm 0.03 \mathrm{a}$ & $20.75 \pm 0.01 \mathrm{a}$ \\
& & TNW & $59.64 \pm 1.76 \mathrm{~b}$ & $54.27 \pm 5.20 \mathrm{a}$ & $12.54 \pm 0.80 \mathrm{~b}$ & $11.82 \pm 0.36 \mathrm{~b}$ \\
\hline \multirow{2}{*}{ Late } & Yungao & CK & $20.53 \pm 0.72 \mathrm{a}$ & $27.79 \pm 0.35 \mathrm{a}$ & $17.66 \pm 0.97 \mathrm{a}$ & $12.30 \pm 0.55 \mathrm{a}$ \\
season & & TNW & $17.77 \pm 0.30 \mathrm{~b}$ & $9.29 \pm 0.46 \mathrm{~b}$ & $13.63 \pm 0.15 \mathrm{~b}$ & $8.69 \pm 1.40 \mathrm{a}$ \\
& Yundi & CK & $23.11 \pm 1.08 \mathrm{a}$ & $15.86 \pm 0.03 \mathrm{a}$ & $16.05 \pm 0.73 \mathrm{a}$ & $16.75 \pm 0.06 \mathrm{a}$ \\
& & TNW & $17.01 \pm 1.18 \mathrm{~b}$ & $14.67 \pm 0.14 \mathrm{~b}$ & $15.09 \pm 0.34 \mathrm{a}$ & $15.05 \pm 1.47 \mathrm{a}$ \\
\hline
\end{tabular}

Means in the same column followed by different lower case letters for the same variety differ significantly at $\mathrm{P}<0.05$ by T-test. AH=after heading; $\mathrm{CK}$ (control); TNW (60 $\mathrm{kg} / \mathrm{hm}^{2}$ nitrogen and water potential of $\left.-(25 \pm 5) \mathrm{kPa}\right)$ were applied at the tilling stage; 60 $\mathrm{kg} / \mathrm{hm}^{2}$ nitrogen and water potential of - $(15 \pm 5) \mathrm{kPa}$ were applied at the booting stage; no nitrogen and water flow of $0 \mathrm{kPa}$ were applied at the grain filling stage).

\section{Correlation analysis}

There existed a significant positive correlation between yield and seed-setting rate $(\mathrm{r}=0.8402, \mathrm{P}<0.01)$ and a significant negative correlation between effective panicles and grain number per panicle $(\mathrm{r}=-0.9335, \mathrm{P}<0.01)$ was observed.

Table 6. Relationship between yield and yield related traits of two rice cultivars

\begin{tabular}{ccccc}
\hline Paramaters & Panicle number per hill & Grains number per panicle & Seed-setting rate & 1000-grain weight \\
\hline Grains number per panicle & $-0.9335^{* *}$ & & \\
Seed-setting rate & 0.3906 & -0.5014 & \\
1000-grain weight & 0.4348 & -0.3419 & 0.0870 & \\
Yield & 0.3979 & -0.4836 & $0.8402^{* *}$ & -0.2389 \\
\hline
\end{tabular}

Significant correlations at $* \mathrm{P}<0.05$ and $* * \mathrm{P}<0.01 . \mathrm{AH}=$ after heading; $\mathrm{MS}=$ maturity stage.

The 2-AP content in grains at maturity was significantly positive correlated to the 2 -AP content in grains at $21 \mathrm{~d} \mathrm{AH}(\mathrm{P}<0.01)$, the 2-AP content in grains at $14 \mathrm{~d} \mathrm{AH}(\mathrm{P}$ $<0.01$ for early season, $\mathrm{P}<0.05$ for late season), and the proline content in grains at $7 \mathrm{~d}$ $\mathrm{AH}$ in early season $(\mathrm{P}<0.05)$. However, the 2-AP content in grain at maturity showed significant negative correlation with the proline content in leaves at $14 \mathrm{~d} \mathrm{AH}(\mathrm{P}<0.05)$, 
the proline content in leaves at $21 \mathrm{~d}$ AH $(\mathrm{P}<0.05$ in early season, $\mathrm{P}<0.01$ in late season)( Fig. 2 a-e).

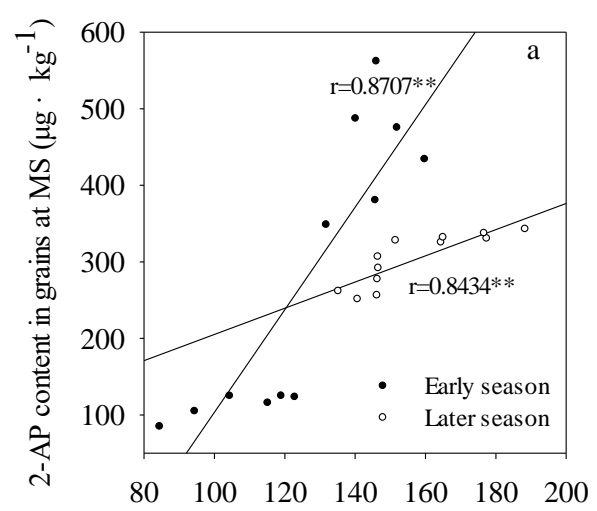

2-AP content in grains at $21 \mathrm{~d} \mathrm{AH}\left(\mu \mathrm{g} \cdot \mathrm{kg}^{-1}\right)$

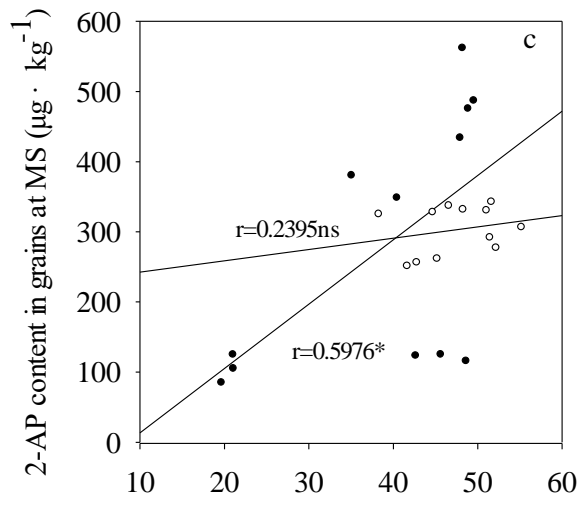

Proline content in grains at $7 \mathrm{~d} \mathrm{AH}\left(\mu \mathrm{g} \cdot \mathrm{g}^{-1}\right)$

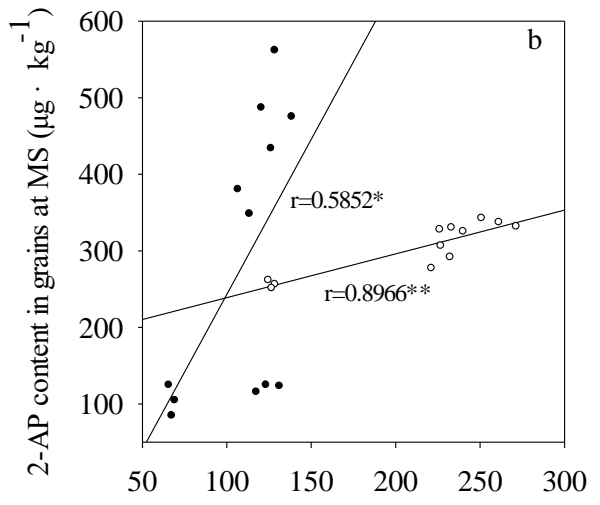

2-AP content in grains at $14 \mathrm{~d} \mathrm{AH}\left(\mu \mathrm{g} \cdot \mathrm{kg}^{-1}\right)$

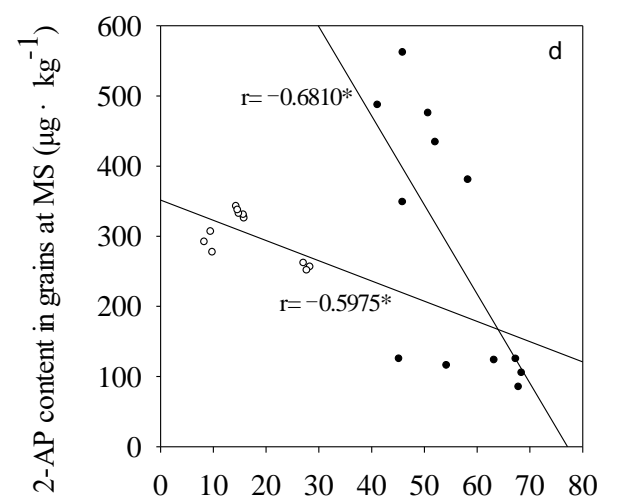

Proline content in leaves at $14 \mathrm{~d} \mathrm{AH}\left(\mu \mathrm{g} \cdot \mathrm{g}^{-1}\right)$

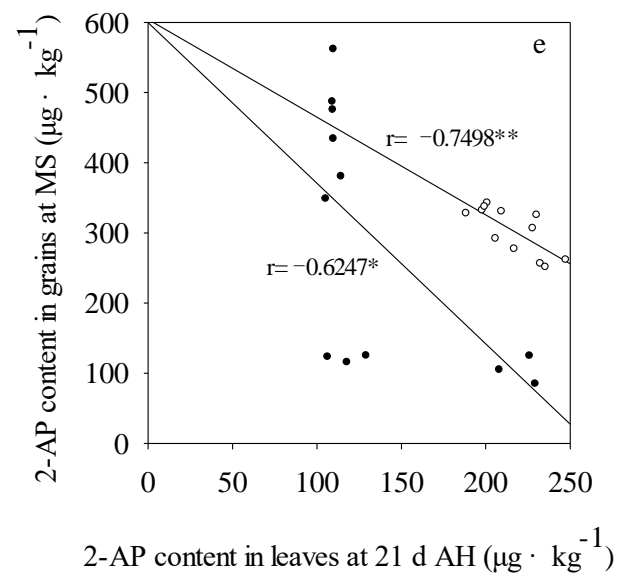

Figure 2. Correlation analyses between the 2-AP content in grains at maturity and $(a)$ the 2-AP content in grains at $21 \mathrm{dAH},(b)$ the $2-A P$ content in grains at $14 \mathrm{dAH},(\mathrm{c})$ the proline content in grains at $7 d \mathrm{AH},(d)$ the proline content in leaves at $14 d \mathrm{AH},(e)$ the 2-AP content in leaves at $21 d$ AH. Significant correlations at $* P<0.05$ and $* * P<0.01$. AH= after heading; $M S=$ maturity stage 
The 2-AP content in leaves at $21 \mathrm{~d} \mathrm{AH}$ showed significant positive correlation with the proline content in leaves at $14 \mathrm{~d} \mathrm{AH}$ and $21 \mathrm{~d} \mathrm{AH}(\mathrm{P}<0.01$ in early season, $\mathrm{P}<0.05$ in later season) (Figure $3 a-b$ ).
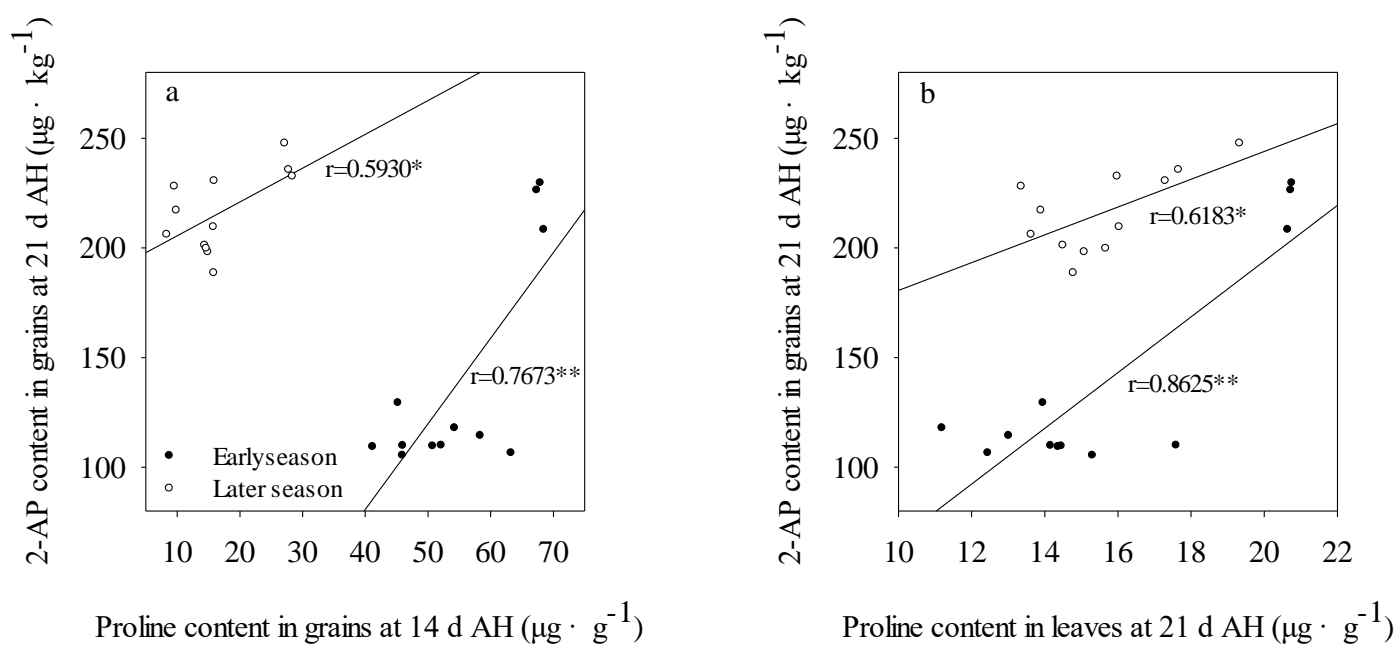

Figure 3. Correlation analyses between the 2-AP content in leaves and proline content in leaves at $14 \mathrm{~d} A H$ and $21 \mathrm{~d}$ AH. Significant correlations at $* P<0.05$ and $* * P<0.01$. AH $=$ after heading; $M S=$ maturity stage

\section{Discussion}

The biosynthesis and accumulation of 2-AP in aromatic rice is an important phenomenon that is affected by several factors (Mo et al., 2016). Precious studies have reported some precursors in the pathways of 2-AP biosynthesis, for example, Seitz et al. (1993) and Huang et al. (2012) found proline was the most important precursor and directly involved in 2-AP formation, then, ornithine and glutamic acid were found to have relevant relationship with the fragrance constitution (Yoshihashi, 2002). The fragrance of aromatic rice is affected by environmental factors, in particular, the irrigation model and nitrogen application. For water irrigation, Wang et al. (2013b) found that moderate soil water potential $(-(25 \pm 5) \mathrm{kPa})$ at the tillering stage significantly enhanced in 2-AP accumulation in grain by $22.70 \%-29.76 \%$. Similar findings were also observed when the soil water potential was $-(25 \pm 5) \mathrm{kPa}$ at the booting stage, the 2-AP content in grain was significantly increased by $35.88 \%-47.02 \%$ (Wang et al., 2013a). Moreover, when the shallow-water irrigation method was applied at grain filling stage, the 2-AP content in grains was markedly increased by $54.80 \%-322.90 \%$ (Tian et al., 2010). The enhancement in 2-AP content in grains was associated to the improvement in proline content in grains (Tian et al., 2010; Wang et al., 2013a,b). Moreover, nitrogen application also has positive influence on the accumulation of proline and 2-AP. Yang et al. (2012) reported higher proline was found in aromatic rice grains which was planted in paddy filed contains higher total nitrogen, and higher proline content contributed to the accumulation of higher aroma. 
Li et al. (2014) found that 2-AP content in grains increased significantly by $10.33 \%-23.50 \%$ when $60 \mathrm{~kg} / \mathrm{hm}^{2}$ nitrogen fertilizer was applied at the tillering stage. Zhong and Tang (2014) also found that the grains 2-AP content was increased, because of the proline concentrations in leaves and grains were improved with the increasing nitrogen application. Meanwhile, the effects of water deficit and nitrogen interaction on proline content have been reported in some previous studies. Lalelou and Fateh (2014) reported that under severe water conditions $\left(60 \%\right.$ field capacity loss) and $80 \mathrm{~kg} / \mathrm{hm}^{2}$ nitrogen, the proline content in flag leaf of wheat was increased (15.76-20.39 fold). All the previous indicated the single water or nitrogen treatment could improve the gain 2-AP content. According our previous studies (data unpublished), we have found the water-nitrogen treatment improved the grain 2-AP content at tillering stage, booting stage, and grain filling stage. In this study, we have further found that 2-AP content in grains was increased by TNW (The treatment management practice involved applying nitrogen $\left(60 \mathrm{~kg} / \mathrm{hm}^{2}\right)$ at tillering stage with heavy drought conditions (water potential of - $(25 \pm 5) \mathrm{kPa}$ ), applying 60 $\mathrm{kg} / \mathrm{hm}^{2}$ nitrogen at the booting stage with feebly arid conditions (water potential of - $(15 \pm 5)$ $\mathrm{kPa}$ ), and applying no nitrogen at the grain filling stage with shallow-watered irrigation (water flow of $0 \mathrm{kPa}$ )) (Table 2). Similarly, the proline concentration in grains at the four sampling stages was increased in early and later seasons (Table 3). Moreover, the 2-AP content in grains at maturity was significantly positive correlated to the 2-AP content in grains at $21 \mathrm{~d} \mathrm{AH}$, the 2-AP content in grains at $14 \mathrm{~d} \mathrm{AH}$, and positive correlation between 2-AP in grain at maturity and proline content in grain at $7 \mathrm{~d} \mathrm{AH}$ was also observed (Fig. $2 a-c, e$ ). This indicated that the TNW treatment can increase 2-AP content in grains at maturity due to the improvement of 2-AP content in grains at $14 \mathrm{~d} \mathrm{AH}$ and 21 $\mathrm{d} \mathrm{AH}$ and the proline content in grains at $7 \mathrm{~d} \mathrm{AH}$.

Interestingly, we observed that the proline content and 2-AP content in leaves at the four sampling stages was decreased (Table 4, 5). Correlation analysis indicated that the 2-AP content in grains at maturity showed significant negative correlation with the proline content in leaves at $14 \mathrm{~d} \mathrm{AH}$ and the proline content in leaves at $21 \mathrm{~d} \mathrm{AH}$ (Fig. $2 d$ ). Further, the 2-AP content in leaves at $21 \mathrm{~d} \mathrm{AH}$ showed significant positive correlation with the proline content in leaves leaf at $14 \mathrm{~d} \mathrm{AH}$ and $21 \mathrm{~d} \mathrm{AH} \mathrm{(Fig.} 3 a-b)$. This suggested that proline or 2-AP may possibly transport from leaves to grains (Buttery et al., 1983; Maraval et al., 2010; Mo et al., 2016).

The water and nitrogen effects on crop yield have been investigated by many researchers (Wang et al., 2003; Cai et al., 2006; Yang et al., 2016). Wang et al. (2016) found that $200 \mathrm{~kg} / \mathrm{hm}^{2}$ nitrogen fertilizer application and alternate wetting and moderate drying regime increased grain yield due to more panicle and more spikelet number of per panicle; $300 \mathrm{~kg} / \mathrm{hm}^{2}$ nitrogen fertilizer application and alternate wetting and serve drying regime treatment increased the number of panicle, spikelet number per panicle and the percentage of filled grains and produced high yield. Li et al. (2014) found that the yield aromatic rice varieties were increased under the interaction of $60 \mathrm{~kg} / \mathrm{hm}^{2}$ nitrogen fertilizer application and water flow of $-10 \mathrm{kPa}$ because of higher seed-setting rate, 1000-grains weight or number of panicles. Our results also confirmed that water and nitrogen applications have a positive effect on the yield of two fragrant rice cultivars. The 
improvement in grain yield is associated to the higher panicle number per hill, seed-setting rate, and 1000 grain weight. Moreover, we found significant positive correlation between grain yield and seed-setting rate $(\mathrm{r}=0.8402, \mathrm{P}<0.01)($ Table 1,6$)$.

\section{Conclusion}

In conclusion, the TNW treatment increased grain yield, and some yield parameters, 2-AP and proline in grains, and led to improve the grain aroma. For revealing the mechanism of 2-AP transportation by irrigation and nitrogen management practice treatment, much work should be done at molecular and physiological level.

Acknowledgements. Founding provide by National Natural Science Foundation of China (31271646), National Natural Science Foundation for Young Scientists (31601244), Guangzhou Science and Technology Plan Project (201707010413) Agricultural Research Projects of Guangdong Province (2011AO20202001), Nature Science Foundation of Guangdong Province (81510642010000017), and Agricultural Standardization Projects of Guangdong Province (4100F10003) is highly acknowledged. We thank LetPub (www.letpub.com) for its linguistic assistance during the preparation of this manuscript.

\section{REFERENCES}

[1] Arora, V. (2006): Application of a rice growth and water balance model in an irrigated semi-arid subtropical environment. - Agricultural water management 83(1): 51-57.

[2] Ashraf, U. Hussain, S., Anjum, S. A., Abbas F., Tanveere, M., Noor, M. A., Tang X. (2017): Alterations in growth, oxidative damage, and metal uptake of five aromatic rice cultivars under lead toxicity. -Plant Physiology and Biochemistry 115: 461-471.

[3] Ashraf, U., Tang, X. (2017): Yield and quality responses, plant metabolism and metal distribution pattern in aromatic rice under lead $(\mathrm{Pb})$ toxicity. -Chemosphere 176: 141-155

[4] Bates, L., Waldren, R., Teare, I. (1973): Rapid determination of free proline for water-stress studies. - Plant and Soil 39(1): 205-207.

[5] Buttery, R., Ling, L., Juliano, B. (1982): 2-Acetyl-1-pyrroline: an important aroma component of cooked rice. - Chemistry and Industry 23: 958-959.

[6] Buttery, R., Ling, L. C., Juliano, B. O., Turnbaugh, J. G. (1983): Cooked rice aroma and 2-acetyl-1-pyrroline. - Journal of Agricultural and Food Chemistry 31(4): 823-826.

[7] Cai, Y., Wang, W., Zhu, Z., Zhang, Z., Lang, Y., Zhu, Q. (2006): Effects of water stress during grain-filling period on rice grain yield and its quality under different nitrogen levels. - Ying Yong Sheng Tai Xue Bao 17(7): 1201-1206. (in Chinese)

[8] Champagne, E. T. (2008): Rice aroma and flavor: a literature review. - Cereal Chem 85(4): 445-454.

[9] Djaman, K., Bado, B. V., Mel, V. C. (2016): Effect of nitrogen fertilizer on yield and nitrogen use efficiency of four aromatic rice varieties. - Emirates Journal of Food and Agriculture 28(2): 126.

[10] Fitzgerald, T. L., Waters, D. L. E., Brooks, L. O., Henry, R. J. (2010): Fragrance in rice (Oryza sativa) is associated with reduced yield under salt treatment. - Environmental and Experimental Botany 68(3): 292-300.

[11] Gay, F., Maraval, I., Roques, S., Gunata, Z., Boulanger, R., Audebert, A. (2010): Effect of salinity on yield and 2-acetyl-1-pyrroline content in the grains of three fragrant rice cultivars (Oryza sativa L.) in Camargue (France). - Field crops research 117(1): 154-160. 
[12] Hakoomat, A., Hasnain, Z., SHAHZAD, A. N., Sarwar, N., Qureshi, M. K., Khaliq, S. (2014): Nitrogen and Zinc Interaction Improves Yield and Quality of Submerged Basmati Rice. - Notulae Botanicae Horti Agrobotanici Cluj-Napoca 42(2): 372.

[13] Huang, Z. L., Tang, X. R., Wang, Y. L., Chen, M. J., Zhao, Z. K., Duan, M. Y. (2012): Effects of increasing aroma cultivation on aroma and grain yield of aromatic rice and their mechanism. - Scientia Agricultura Sinica 45(6): 1054-1065. (in Chinese)

[14] Lalelou, F. S., Fateh, M. (2014): Effects of Water Deficit Stress and Nitrogen Fertilizer on Wheat Varieties. - International Journal of Bioscience 4(9): 183-189.

[15] Lei, S., Wang, C. C., Ashraf, U., Mo, Z. W., Namaw, M., Ashraf, I., Muzaffar, W., Liu, S. J., Tang, X. R. (2017): Exogenous application of mixed micro-nutrients improves yield, quality and 2-acetyl-1-pyrroline contents in fragrant rice. - Applied Ecology and Environmental Research 15(3): 1097-1109.

[16] Li, M., Ashraf, U., Tian, H., Mo, Z., Pan, S., Anjum, S. A. (2016): Manganese-induced regulations in growth, yield formation, quality characters, rice aroma and enzyme involved in 2-acetyl-1-pyrroline biosynthesis in fragrant rice. - Plant Physiology and Biochemistry 103: 167-175.

[17] Li , Y. H., Tang, X. R., Pan, S. G., Yang, X. J. (2014): Effect of water-nitrogen interaction at tillering stage on aroma, grain yield and quality of aromatic rice. - Acta Agriculturae Boreali-Sinica 29(1): 159-164. (in Chinese)

[18] Mahajan, G., Sekhon, N., Singh, N., Kaur, R., Sidhu, A. (2010): Yield and nitrogen-use efficiency of aromatic rice cultivars in response to nitrogen fertilizer. - Journal of New Seeds 11(4): 356-368.

[19] Maraval, I., Sen, K., Agrebi, A., Menut, C., Morere, A., Boulanger, R. (2010): Quantification of 2-acetyl-1-pyrroline in rice by stable isotope dilution assay through headspace solid-phase microextraction coupled to gas chromatography-tandem mass spectrometry. - Analytica chimica acta 675(2): 148-155.

[20] Mo, Z. W., Huang, J., Xiao, D., Ashraf, U., Duan, M. Y., Pan, S. G. (2016): Supplementation of 2-Ap, $\mathrm{Zn}$ and La improves 2-acetyl-1-pyrroline concentrations in detached aromatic rice panicles in vitro. - PloS one 11(2): e0149523.

[21] Mo, Z. W., Lei, S., Ashraf, U., Khan, I., Li, Y., Pan, S. G., Duan, M. Y., Tian, H., Tang, X. R. (2017): Silicon fertilization modulates 2-acetyl-1-pyrroline content, yield formation and grain quality of aromatic rice. - Journal of Cereal Science 75: 17-24.

[22] Mo, Z. W., Li, W., Pan, S. G., Fitzgerald, T. L., Xiao, F., Tang, X. R. (2015): Shading during the grain filling period increases 2-acetyl-1-pyrroline content in fragrant rice. Rice 8(1): 9.

[23] Mohammed, A. R., Tarpley, L. (2010): Effects of high night temperature and spikelet position on yield-related parameters of rice (Oryza sativa L.) plants. - European Journal of Agronomy 33(2) : 117-123.

[24] Nagarajan, S., Jagadish, S., Prasad, A. H., Thomar, A., Anand, A., Pal, M. (2010): Local climate affects growth, yield and grain quality of aromatic and non-aromatic rice in northwestern India. - Agriculture, Ecosystems and Environment 138(3): 274-281.

[25] Poonlaphdecha, J., Maraval, I., Roques, S., Audebert, A., Boulanger, R., Bry, X. (2012): Effect of timing and duration of salt treatment during growth of a fragrant rice variety on yield and 2-Acetyl-1-pyrroline, proline, and GABA levels. - Journal of agricultural and food chemistry 60(15): 3824-3830.

[26] Seitz, L. M., Wright, R. L., Waniska, R. D., Rooney, L. W. (1993): Contribution of 2-acetyl-1-pyrroline to odors from wetted ground pearl millet. - Journal of Agricultural and Food Chemistry 41(6): 955-958.

[27] Sikdar, M. S. I., Rahman, M. M., Islam, M. S., Yeasmin, M. S., Akhter, M. M. (2008): Effect of nitrogen level on aromatic rice varieties and soil fertility status. - International Journal of Sustainable Crop Production 3(3): 49-54. 
[28] Summart, J., Thanonkeo, P., Panichajakul, S., Prathepha, P., McManus, M: (2010). Effect of salt stress on growth, inorganic ion and proline accumulation in Thai aromatic rice, Khao Dawk Mali 105, callus culture. - African Journal of Biotechnology 9(2): 145-152

[29] Tian, H., Pan, S. G., Duan, M. Y., Chen, S. J., Tang, X. R. (2014): Effects of water treatment on aroma content, yield and quality of aromatic rice. - Journal of Irrigation and Drainage 33(3): 130-132. (in Chinese)

[30] Tian, K., Tang, X. R., Duan, M. Y., Zhong, K. Y., Li, G. X., Tian, H. (2010): Effects of irrigation on aroma content and physiological characteristics of aromatic rice at grain filling stage. - Journal of Irrigation and Drainage 29(6): 91-93. (in Chinese)

[31] Wang, P., Tang, X.R., Tian, H., Pan, S.G., Duan, M.Y., Nie, J. (2013a): Effects of different irrigation modes on aroma content of aromatic rice at booting stage. Guangdong Agric Sci 40(8): 1-3. (in Chinese)

[32] Wang, P., Xiao, L. Z., Tang, X. R., Tian, H., Pan, S. G., Duan, M. Y. (2013b): Effects of different irrigation modes on aroma content of aromatic rice at tillering stage. - Journal of Irrigation and Drainage 32(1): 103-105. (in Chinese)

[33] Wang, S., Cao, W., Ding, Y., Tian, Y., Jiang, D. (2003): Interactions of water management and nitrogen fertilizer on nitrogen absorption and utilization in rice. Zhongguo nongye kexue 34(4): 497-501. (in Chinese)

[34] Wang, Z., Zhang, W., Beebout, S. S., Zhang, H., Liu, L., Yang, J. (2016): Grain yield, water and nitrogen use efficiencies of rice as influenced by irrigation regimes and their interaction with nitrogen rates. - Field Crops Research, 193: 54-69.

[35] Widjaja, R., Craske, J.D., Wootton, M. (1996): Comparative studies on volatile components of non-fragrant and fragrant rices. - Journal of the Science of Food and Agriculture 70(2): 151-161.

[36] Yajima, I., Yanai, T., Nakamura, M., Sakakibara, H., Hayashi, K. (1979): Volatile flavor components of cooked kaorimai (scented rice, O. sativa japonica). - Agricultural and Biological Chemistry 43(12): 2425-2429.

[37] Yang, J., Zhou, Q., Zhang, J. (2016): Moderate wetting and drying increases rice yield and reduces water use, grain arsenic level, and methane emission. - The Crop Journal 5(2): 151-158.

[38] Yang, S., Zou, Y., Liang, Y., Xia, B., Liu, S., Ibrahim, M. (2012): Role of soil total nitrogen in aroma synthesis of traditional regional aromatic rice in China. - Field Crops Research 125: 151-160.

[39] Yoshihashi, T. (2002): Quantitative analysis on 2-acetyl-1-pyrroline of an aromatic rice by stable isotope dilution method and model studies on its formation during cooking. Journal of food science 67(2): 619-622.

[40] Yoshihashi, T., Kabaki, N., Nguyen, T., Inatomi, H. (2002): Formation of flavor compound in aromatic rice and its fluctuations with drought stress. - Research Highlights JIRCAS 2003(2004): 32-33.

[41] Zhang, T., Zheng, J., Xu, J., Jiang, K., Wu, X., Wang, X. (2008): Genetic diversity of aromatic rice varieties based on markers of functional genes and SSR. - Scientia Agricultura Sinica 41(3): 625-635. (in Chinese)

[42] Zhang, Y., Tang, Q., Peng, S., Xing, D., Qin, J., Laza, R. C. (2012): Water use efficiency and physiological response of rice cultivars under alternate wetting and drying conditions. - The Scientific World Journal 2012.

[43] Zhong, Q., Tang, X. R. (2014): Effects of nitrogen application on aroma of aromatic rice and their mechanism. - Guangdong Agric. Sci. 41(4) 85-87. (in Chinese) 